\title{
Risk factors for hip fracture
}

\author{
Shih-Wei Lai ${ }^{1,2}$ \\ Received: 5 September 2021 / Accepted: 29 September 2021 / Published online: 4 October 2021 \\ (c) International Osteoporosis Foundation and National Osteoporosis Foundation 2021
}

Recently one retrospective study in Japan conducted by Koseki et al. published in Archives of Osteoporosis reported the risk factors for hip fracture in people $\geq 35$ years old, including female, older age, indoors, and living room [1]. Particularly, older people aged $\geq 80$ accounted for $70.9 \%$ of hip fracture cases [1]. Some points are discussed to support Koseki et al.'s findings.

First, fall risk-increasing drugs were found to be associated with an increased probability of hip fracture in older people, for example, opioids, dopaminergic drugs, anxiolytics, antidepressants, and hypnotics/sedatives [2]. As long as the fall does not happen, hip fracture is less likely to develop in older people. Strategies to prevent falls should be initiated in older people who took fall risk-increasing drugs. The database used in Koseki et al.'s study should have the record of these medications. Second, polypharmacy was found to be associated with an increased probability of falls and hip fracture in older people [3, 4]. Although there is no standard definition of polypharmacy for predicting falls, it is suitable to define polypharmacy as taking five or more drugs daily in older people [5]. As the age is increasing, the number of chronic diseases and the number of medications will increase in older people [6-8]. Among older people, the proportions of aging, multimorbidity, and polypharmacy are increased in parallel [8]. The prevalence of polypharmacy ( $\geq 5$ prescribed drugs) was at least $60 \%$ in older people aged $>80$ in Kostev et al.'s study [6]. Such a trend partially explains the result of Koseki et al.'s study that older people aged $\geq 80$ accounted for $70.9 \%$ of hip fracture cases [1]. The database used in Koseki et al.'s study should have the record of polypharmacy. Third, going to the toilet is a traditional risk factor for hip fracture in older people [9]. But Koseki et al.'s study reported that in the house, the living room and corridor were places where hip fracture often occurred, rather than the toilet or bathroom [1]. This is a novel finding. Strategies to reduce

Shih-Wei Lai

wei@mail.cmuh.org.tw

1 Department of Public Health, College of Public Health, and School of Medicine, College of Medicine, China Medical University, Taichung, Taiwan

2 Department of Family Medicine, China Medical University Hospital, No 2, Yu-De Road, Taichung City 404, Taiwan obstacles in the living room and corridor are a new issue. Finally, I appreciate that Koseki et al.'s study has drawn much attention from researchers engaged in this field.

\section{Declarations}

Conflict of interest None.

\section{References}

1. Koseki H, Sunagawa S, Noguchi C, Yonekura A, Matsumura U, Watanabe $\mathrm{K}$ et al (2021) Incidence of and risk factors for hip fracture in Nagasaki, Japan from 2005 to 2014. Arch Osteoporos 16:111

2. Thorell K, Ranstad K, Midlöv P, Borgquist L, Halling A (2014) Is use of fall risk-increasing drugs in an elderly population associated with an increased risk of hip fracture, after adjustment for multimorbidity level: a cohort study. BMC Geriatr 14:131

3. Kojima T, Akishita M, Nakamura T, Nomura K, Ogawa S, Iijima $\mathrm{K}$ et al (2012) Polypharmacy as a risk for fall occurrence in geriatric outpatients. Geriatr Gerontol Int 12:425-430

4. Lai SW, Liao KF, Liao CC, Muo CH, Liu CS, Sung FC (2010) Polypharmacy correlates with increased risk for hip fracture in the elderly: a population-based study. Medicine (Baltimore) 89:295-299

5. Gnjidic D, Hilmer SN, Blyth FM, Naganathan V, Waite L, Seibel MJ et al (2012) Polypharmacy cutoff and outcomes: five or more medicines were used to identify community-dwelling older men at risk of different adverse outcomes. J Clin Epidemiol 65:989-995

6. Kostev K, Jacob L (2018) Multimorbidity and polypharmacy among elderly people followed in general practices in Germany. Eur J Intern Med 55:66-68

7. Lai SW, Lin CL, Lin CH (2019) Long-term trend of polypharmacy in older people in Taiwan from 2000 to 2013. J Am Geriatr Soc 67:408-409

8. Lai SW, Liao KF, Lin CL, Lin CC, Lin CH (2020) Longitudinal data of multimorbidity and polypharmacy in older adults in Taiwan from 2000 to 2013. Biomedicine (Taipei) 10:1-4

9. Allander E, Gullberg B, Johnell O, Kanis JA, Ranstam J, Elffors L (1996) Falls and hip fracture. A reasonable basis for possibilities for prevention? Some preliminary data from the MEDOS study Mediterranean Osteoporosis Study. Scand J Rheumatol Suppl 103:49-52

Publisher's note Springer Nature remains neutral with regard to jurisdictional claims in published maps and institutional affiliations. 